\title{
Ganho compensatório de novilhas mestiças suplementadas em pastagens sob avaliação do perfil hormonal e parâmetros sanguíneos
}

\section{Compensatory gain of crossbred heifers supplemented in pastures under evaluation hormonal profile and blood parameters}

\author{
Geraldo Trindade Júnior ${ }^{1 *}$; Robério Rodrigues Silva ${ }^{1}$; Gleidson Giordano \\ Pinto de Carvalho ${ }^{2}$; Fabiano Ferreira da Silva ${ }^{3}$; João Alberto Negrão \\ Daniele Soares Barroso ; Daniel Lucas Santos Dias ${ }^{6}$; Patrícia Barcellos Costa
}

\begin{abstract}
Resumo
Objetivou-se com este experimento verificar o efeito do manejo nutricional que alterna períodos de restrição energética/proteica e realimentação de novilhas mestiças em pastejo, durante a pré-puberdade, sobre o perfil hormonal e parâmetros sanguíneos. O estudo foi conduzido na fazenda Princesa do Mateiro, em Ribeirão do Largo, na região Sudoeste do estado da Bahia. Foram utilizadas 20 novilhas mestiças 5/8 Guzerá Leiteiro x 3/8 Holandês, com idade média de 12 meses e peso corporal médio de $187 \pm 13,74 \mathrm{~kg}$, ao início do experimento. Teve duração de 238 dias, sendo 14 destinados à adaptação dos animais. Os animais foram mantidos em pastejo sob lotação rotacionada em pastos de Brachiaria brizantha cv. Marandú e aleatoriamente alocados em dois sistemas nutricionais: Controle (T100) = animais recebendo suplemento concentrado para suprir $100 \%$ da exigência de nutrientes para ganho de $750 \mathrm{~g} \mathrm{dia}^{-1}$ de peso vivo e Nutrição Compensatória (NC). Os animais do sistema nutricional NC alternaram períodos de Restrição $(\mathrm{T} 80)=$ recebendo suplemento concentrado para suprir $80 \%$ da exigência de nutrientes do (T100) e Realimentação $(\mathrm{T} 120)$ = recebendo suplemento concentrado para suprir $120 \%$ das exigências de nutrientes do (T100). As concentrações plasmáticas finais de IGF-I, glicose e uréia foram superiores $(\mathrm{P}<0,05)$ nos animais submetidos à Nutrição Compensatória $(\mathrm{NC})$. Os níveis de insulina, colesterol, progesterona e proteína não sofreram variações $(\mathrm{P}>0,05)$ entre os animais dos sistema nutricionais Controle e NC. Houve correlações positivas $(\mathrm{P}<0,05)$ entre o IGF-I, insulina, glicose e colesterol e correlação negativa $(\mathrm{P}<0,05)$ entre IGF-I e uréia. Houve correlação positiva $(\mathrm{P}<0,05)$ da insulina com a glicose. Ocorreu correlação positiva $(\mathrm{P}<0,05)$ da glicose com o colesterol. Houve correlação negativa $(\mathrm{P}<0,05)$ da uréia com o colesterol, progesterona e proteína. A progesterona também apresentou correlação positiva $(\mathrm{P}<0,05)$ com a proteína.
\end{abstract}

Palavras-chave: Hormônios, metabólitos, restrição, realimentação, bovino

\footnotetext{
Zootecnistas, Profs. Drs., Universidade Estadual do Sudoeste da Bahia, UESB, campus de Itapetinga, BA. E-mail: geraldouesb@ yahoo.com.br; rrsilva.uesb@hotmail.com

2 Zootecnista, Prof. Dr.,Universidade Federal da Bahia, UFBA, Salvador, BA. E-mail: gleidsongiordano@yahoo.com.br

3 Médico Veterinário, Prof. Dr., UESB, campus de Itapetinga, BA. E-mail: ffsilva@cnpq.com.br

4 Zootecnista, Prof. Dr., Universidade de São Paulo, USP, campus de Pirassununga, SP. E-mail: jnegrao@usp.br

5 Zootecnista, Discente de Mestrado, UESB, campus de Itapetinga, BA. E-mail: dani_mineirinha@hotmail.com

6 Zootecnista, Discente de Doutorado,UESB, campus de Itapetinga, BA. E-mail: daniel_zootecnia@hotmail.com

7 Médica Veterinária, Prof ${ }^{\mathrm{a}} \mathrm{Dr}^{\mathrm{a}}$, Universidade Estadual do Oeste do Paraná, UNIOESTE, campus de Marechal Cândido Rondon, PR. E-mail: patriciabarc@ibest.com.br

* Autor para correspondência
} 


\begin{abstract}
The objective of this experiment was to verify the effect of nutritional management that alternates periods of energy/protein restriction and refeeding of grazing crossbred heifers during their prepuberty on the hormonal profile and blood parameters. The study was conducted at Princesa do Mateiro farm in Ribeirão do Largo, in the southwest region of the state of Bahia. Twenty crossbred heifers 5/8 Dairy Guzerat x 3/8 Dutch with an average age of 12 months and average body weight of $187 \pm 13.74 \mathrm{~kg}$ were used at the beginning of the experiment. It lasted 238 days, 14 out of them were for the animals' adaptation. The animals were kept in rotational grazing of Brachiariabrizantha cv. Marandú pastures and randomly assigned to two treatments: Control $(\mathrm{T} 100)=$ animals receiving concentrate supplement to supply $100 \%$ of the nutrients requirement to gain $750 \mathrm{~g}^{\text {day }}{ }^{-1}$ of live weight and Compensatory Nutrition $(\mathrm{CN})$. The animals of the $\mathrm{CN}$ treatment alternated periods of Restriction $(\mathrm{T} 80)=$ receiving concentrate supplement to meet $80 \%$ of the demand for nutrients of the (T100) and periods of Refeeding $(\mathrm{T} 120)=$ getting concentrate supplement to supply $120 \%$ of the nutrient requirements of the (T100 The final plasma concentrations of IGF-I, glucose and urea were higher $(\mathrm{P}<0.05)$ in the animals undergoing compensatory nutrition $(\mathrm{CN})$ treatment. The insulin, cholesterol, progesterone and protein levels of the animals from Control and $\mathrm{CN}$ nutritional systems did not changed $(\mathrm{P}>0.05)$. There were positive correlations $(\mathrm{P}<0.05)$ between IGF-I, insulin, glucose and cholesterol, and a negative correlation $(\mathrm{P}<0.05)$ between IGF-I and urea. There were also positive correlation $(\mathrm{P}<0.05)$ between insulin and glucose and positive correlation $(\mathrm{P}<0.05)$ between glucose and cholesterol. There was a negative correlation $(\mathrm{P}<0.05)$ of the urea with cholesterol, progesterone and protein. Progesterone also showed a positive correlation $(\mathrm{P}<0.05)$ with the protein.
\end{abstract}

Key words: Hormones, metabolites, restriction, refeeding, cattle

\section{Introdução}

A mensuração de variáveis metabólicas plasmáticas dentro dos estudos de nutrição animal tem contribuído na obtenção de conclusões mais seguras sobre alterações metabólicas derivadas das mudanças promovidas no manejo alimentar dos animais. Dessa forma a utilização do perfil metabólico consolidou-se passando a despertar maior interesse zootécnico como método auxiliar na avaliação de rebanhos com diferentes índices produtivos e reprodutivos, apesar das dificuldades da utilização e interpretação desta ferramenta, devido à escassez de valores de referência adequados pelo reduzido quantitativo de pesquisas com metabólitos e hormônios e suas correlações com o crescimento compensatório de bovinos.

Sendo assim, os estudos envolvendo os níveis plasmáticos e correlações fisiológicas de metabólitos sanguíneos têm sido usadas com o intuito de demonstrar suas relações e efeitos sobre os bovinos e como a suplementação nutricional pode alterar seus padrões (OLIVEIRA FILHO; GAMBARINI; TONIOLLO, 1997).
Para a avaliação das mudanças do status endócrino associadas com o manejo compensatório, têm sido medida a concentração de hormônio do crescimento (GH), insulina e triglicérides no soro (PARK et al., 1987). Outros metabólitos sanguíneos também estão sendo avaliados para medir os reflexos do manejo compensatório sobre a produção do tecido mamário e idade à puberdade (WHITLOCK et al., 2002). Para os autores a maior meta no programa de reposição de vacas leiteiras deveria ser a produção de novilhas com adequado desenvolvimento da glândula mamária e não somente o aumento da eficiência de crescimento corporal.

Dessa forma objetivou-se com esta pesquisa verificar o efeito do manejo nutricional com alternância de períodos de restrição energética/ proteica e realimentação, durante a pré-puberdade de novilhas mestiças em pastejo, sobre alterações metabólicas sanguíneas dos animais e contribuir com novas informações que auxiliem no conhecimento mais detalhado de tão complexa teia de relações metabólicas. 


\section{Material e Métodos}

O experimento foi conduzido na fazenda Princesa do Mateiro, no município de Ribeirão do Largo, localizado na região Sudoeste do estado da Bahia. Foram utilizadas 20 novilhas mestiças com grau de sangue 5/8 Guzerá Leiteiro x 3/8 Holandês, com média de 12 meses de idade inicial e peso corporal médio inicial de $187 \pm 13,74 \mathrm{~kg}$. Os animais foram pesados e aleatoriamente alocados em cada um dos sistemas nutricionais com 10 repetições segundo o delineamento inteiramente casualizado.

O estudo teve duração de 238 dias, com 14 destinados à adaptação e 224 divididos em 4 subperíodos de 56 dias, sendo o $1^{\circ}$ e o $3^{\circ}$ de restrição e o $2^{\circ}$ e $4^{\circ}$ de realimentação.

Descrição dos sistemas nutricionais a partir do nível de atendimento da exigência de nutrientes digestíveis totais e proteína:

Sistema Nutricional Controle (T100): 10 (dez) animais receberam suplemento concentrado para suprir $100 \%$ da exigência de nutrientes para ganho de peso de $750 \mathrm{~g} \mathrm{dia}^{-1}$ (NRC, 2001), ao nível de
$2,5 \% \mathrm{PV}$.

Sistema Nutricional Nutrição Compensatória (NC): 10 (dez) animais alternaram períodos de restrição e realimentação. No $1^{\circ}$ e $3^{\circ}$ períodos, os animais do sistema nutricional (NC) receberam suplementação referente ao T80 e no $2^{\circ}$ e $4^{\circ}$ períodos, receberam suplementação referente ao T120: Restrição (T80) = Os animais receberam suplemento concentrado para suprir $80 \%$ da exigência de nutrientes digestíveis totais (NDT) e proteína do sistema nutricional Controle. Realimentação (T120) $=$ Os animais receberam suplemento concentrado para suprir $120 \%$ das exigências de NDT e proteína do sistema nutricional Controle.

O suplemento concentrado (Tabela 1) foi formulado para suplementar a exigência dos animais para mantença e ganho de peso de $750 \mathrm{~g}^{\mathrm{dia}^{-1}}$ (NRC, 2001), ao nível de 2,5\% PV e ajustado para o sistema nutricional. A suplementação foi fornecida diariamente, sempre às 10:00 horas, em cochos plásticos coletivos, com duplo acesso, sem cobertura, com dimensionamento linear de $80 \mathrm{~cm}^{\text {animal }}{ }^{-1}$.

Tabela 1. Proporções de ingredientes do suplemento concentrado por período experimental.

\begin{tabular}{lcccc}
\hline \multicolumn{1}{c}{$\begin{array}{c}\text { Ingrediente } \\
(\%)\end{array}$} & $1^{\text {o }}$ & $2^{\text {o }}$ & $3^{\text {Períodos }}$ & $4^{\text {o }}$ \\
\hline Milho grão moído & 28,20 & 66,47 & 70,52 & 72,05 \\
Farelo de soja & 34,08 & 26,75 & 25,92 & 25,21 \\
Farelo de trigo & 35,20 & 5,28 & 0,08 & - \\
Calcário calcítico & 1,32 & - & 0,67 & 0,84 \\
Fosfato bicálcico & - & - & 0,51 & - \\
Uréia & - & - & - & 0,36 \\
Suplemento mineral ${ }^{1}$ & 1,20 & 1,50 & 2,30 & 1,54 \\
\hline
\end{tabular}

${ }^{1}$ Composição por cada $1.000 \mathrm{~g}$ : Cálcio $140 \mathrm{~g}$; fósforo $65 \mathrm{~g}$; sódio $148 \mathrm{~g}$; magnésio $5 \mathrm{~g}$; enxofre $12 \mathrm{~g}$; cobalto $107 \mathrm{mg}$; cobre 1.550 mg; iodo $150 \mathrm{mg}$; manganês $1.400 \mathrm{mg}$; níquel $30 \mathrm{mg}$; selênio $18 \mathrm{mg}$; zinco 4.500 mg; 1.120 mg; flúor (máximo) $650 \mathrm{mg}$.

Fonte: Elaboração dos autores.

Os animais foram mantidos a pasto, numa área experimental de 10 ha, dividida em quatro piquetes de 2,5 ha cada, com cobertura uniforme de Brachiariabrizantha cv. Marandú, sem qualquer correção ou adubação. O solo foi coletado e analisado 30 dias antes do início do experimento (Tabela 2).
Usou-se o sistema de pastejo sob lotação rotacionada, com utilização continua de dois piquetes por vez por período de 28 dias, alternando 28 dias de descanso. Os piquetes foram vedados 30 dias antes do início do experimento, permitindo que, ao início do experimento, todos os piquetes tivessem quantidades de forragem similares. 
Foi adotado o método de lotação contínua com mesma carga animal para reduzir a influência da variação de biomassa entre piquetes. As novilhas permaneceram em cada piquete por sete dias e, após esse período, alternava-se com o piquete do outro sistema nutricional. Depois de 28 dias os dois lotes de animais eram conduzidos para outros dois piquetes e reiniciava-se o rodízio de sete dias entre eles. Os dois piquetes vedados por 28 dias funcionavam como gaiolas de exclusão.

Tabela 2. Características químicas e físicas do solo da área experimental.

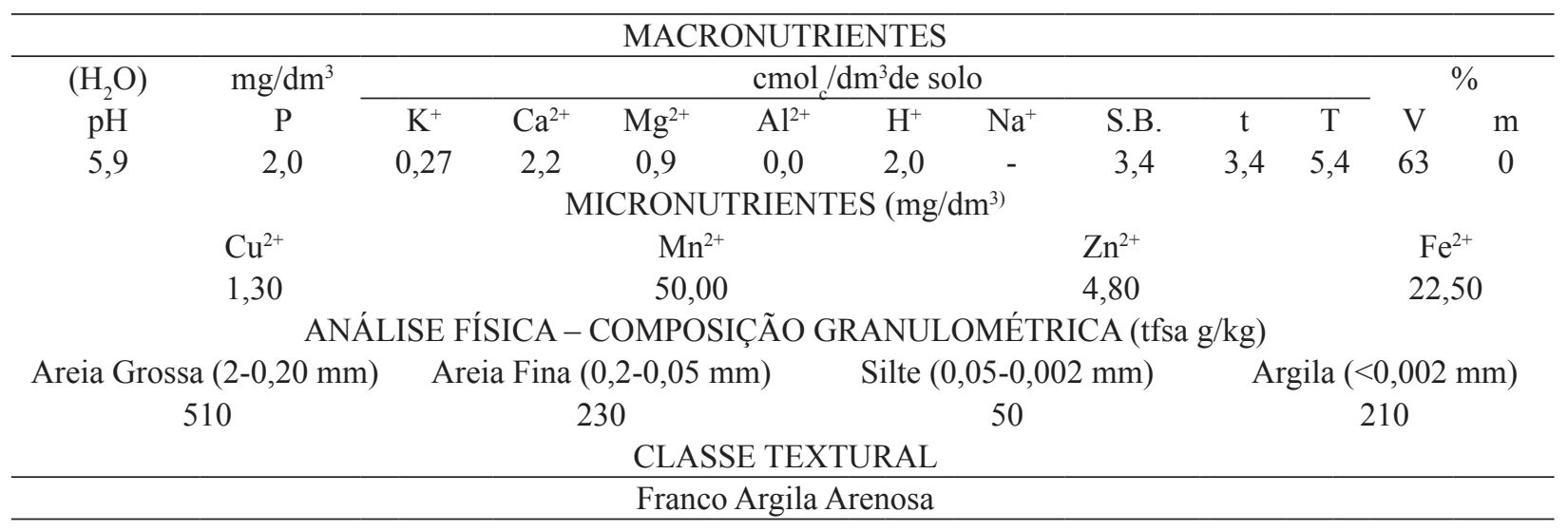

S.B.= soma de bases trocáveis; $\mathrm{t}=\mathrm{CTC}$ efetiva; $\mathrm{T}=\mathrm{CTC}$ a $\mathrm{pH}$ 7,0; $\mathrm{V}=$ saturação por bases; $\mathrm{m}=$ saturação por Alumínio.

Fonte: Elaboração dos autores.

$\mathrm{Na}$ Tabela 3 é apresentada a composição bromatológica da forragem, com os teores de matéria seca (MS), matéria orgânica (MO), proteína bruta (PB), extrato etéreo (EE) cinzas (CZ) obtidos conforme metodologias descritas por AOAC (1995), fibra em detergente neutro (FDN) e fibra em detergente ácido (FDA) obtidos conforme metodologias descritas por Van Soest, Robertson e Lewis (1991). O teor de FDN corrigido para cinzas e proteínas (FDNcp) foi realizado segundo recomendações de Mertens (2002). Os carboidratos totais (CHOT) foram obtidos pela equação: 100 - (\%PB + \%EE + \%Cinzas) (SNIFFEN et al., 1992), enquanto os carboidratos não fibrosos (CNF), pela diferença entre CHOT e FDNcp. Os teores de nutrientes digestíveis totais (NDT) foram calculados segundo Weiss (1999), utilizando a FDNcp e os CNF, pela equação: NDT $(\%)=$ PBD + FDNcpD + CNFD + 2,25 EED. Onde: PBD $=$ PB digestível; FDNcpD = FDNcp digestível; CNFD = $\mathrm{CNF}$ digestíveis; e EED = EE digestível.
As amostras do pastejo simulado foram obtidas pela observação dos animais experimentais conforme Johnson (1978), identificando-se visualmente o tipo de material consumido e coletando-se uma amostra semelhante ao alimento ingerido.

O pasto foi avaliado a cada 28 dias. Para estimar a disponibilidade de MS foram tomadas 12 amostras por piquete, cortadas ao nível do solo com um quadrado de $0,25 \mathrm{~m}^{2}$, conforme metodologia descrita por McMeniman (1997), (Tabela 4). As amostras foram pesadas em balança portátil com precisão de $5 \mathrm{~g}$, e em seguida unificadas para formação da amostra composta dos piquetes que estavam sob pastejo e outra composta dos piquetes sem utilização dos animais. Retirou-se amostras em duplicatas, uma foi acondicionada em saco plástico, identificada e congelada à $-10^{\circ} \mathrm{C}$, e a outra foi utilizada para separação manual dos componentes (folha, colmo e material morto), os quais foram pesados para obter o percentual de cada componente e armazenados em sacos plásticos previamente identificados e 
congelados $\mathrm{a}-10^{\circ} \mathrm{C}$, sendo depois analisados para determinação da composição química. O percentual de cada componente na forragem foi calculado pela matéria seca (MS) da amostra de cada componente dividida pela MS da amostra total.

Tabela 3. Composição bromatológica das amostras da forragem coletadas por pastejo simulado (PS), e do suplemento (SUP) nos respectivos períodos experimentais.

\begin{tabular}{lcccccccc}
\hline \multirow{2}{*}{\begin{tabular}{l} 
Item \\
\multicolumn{1}{c}{$\%)$}
\end{tabular}} & \multicolumn{7}{c}{ P } & \multicolumn{7}{c}{$1^{\circ}$} & \multicolumn{7}{c}{$2^{\circ}$} & \multicolumn{1}{c}{$3^{\circ}$} & & $4^{\circ}$ \\
\cline { 2 - 9 } & PS & SUP & PS & SUP & OS & SUP & PS & SUP \\
\hline MS & 27,45 & 91,23 & 25,34 & 90,56 & 40,05 & 90,45 & 24,87 & 90,76 \\
PB & 12,23 & 22,56 & 11,09 & 20,26 & 8,78 & 19,49 & 15,13 & 20,20 \\
EE & 2,65 & 2,89 & 2,76 & 2,67 & 2,35 & 3,45 & 2,69 & 3,65 \\
CHOT & 82,56 & 75,27 & 83,76 & 76,80 & 87,87 & 75,65 & 84,04 & 74,83 \\
CNF & 20,78 & 58,71 & 18,56 & 57,42 & 14,78 & 55,65 & 17,34 & 54,83 \\
FDNcp & 72,08 & 15,31 & 75,73 & 17,48 & 78,39 & 16,08 & 67,75 & 16,88 \\
FDA & 32,05 & 4,89 & 34,98 & 5,11 & 37,62 & 5,17 & 30,97 & 5,52 \\
CZ & 5,78 & 4,95 & 6,09 & 5,05 & 6,20 & 5,03 & 5,89 & 55,15 \\
NDT & 69,07 & 77,19 & 68,35 & 81,63 & 58,79 & 80,5 & 67,89 & 81,2 \\
\hline
\end{tabular}

Matéria seca (MS), matéria orgânica (MO), proteína bruta (PB), extrato etéreo (EE) cinzas (CZ) obtidos conforme metodologias descritas por AOAC (1995), fibra em detergente neutro (FDN) e fibra em detergente ácido (FDA) obtidos conforme metodologias descritas por Van Soest, Robertson e Lewis (1991). O teor de FDN corrigido para cinzas e proteínas (FDNcp) foi realizado segundo recomendações de Mertens (2002). Os carboidratos totais (CHOT) foram obtidos pela equação: $100-(\% \mathrm{~PB}+\% \mathrm{EE}+\% \mathrm{Cinzas})$ (Sniffen et al., 1992), enquanto os carboidratos não fibrosos (CNF), pela diferença entre CHOT e FDNcp. Os teores de nutrientes digestíveis totais (NDT) foram calculados segundo Weiss (1999), utilizando a FDNcp e os CNF, pela seguinte equação: NDT (\%) $=\mathrm{PBD}+$ FDNcpD + CNFD + 2,25 EED Onde: $\mathrm{PBD}=\mathrm{PB}$ digestível; FDNcpD $=$ FDNcp digestível; $\mathrm{CNFD}=\mathrm{CNF}$ digestíveis; e $\mathrm{EED}=$ EE digestível.

Fonte: Elaboração dos autores.

Tabela 4. Disponibilidade da forragem e seus constituintes.

\begin{tabular}{lcccc}
\hline \multicolumn{1}{c}{ Item } & $1^{\text {o }}$ & $2^{\text {o }}$ & $3^{\text {Períodos }}$ & $4^{\text {o }}$ \\
\hline DMST (kg/ha) & 3474 & 2967 & 1910 & 3898 \\
DMSV (kg/ha) & 2758 & 1902 & 1266 & 2158 \\
DMSpd (kg/ha) & 2686 & 2207 & 1193 & 2898 \\
DFDNpd (kg/ha) & 1563 & 1335 & 725 & 1637 \\
BRD (kg MS/ha/dia) & 83 & 88 & 60 & 122 \\
TL (UA/ha) & 0,92 & 1,12 & 1,28 & 1,38 \\
TAD (kg MS/ha/dia) & 30 & 23 & -19 & 80 \\
OF (kg MS/100 kg PC/dia) & 33 & 26 & 8 & 39 \\
AF (cm) & 39 & 31 & 15 & 46 \\
\% Folha & 40,3 & 24,2 & 24,3 & 43,3 \\
\% Colmo & 39,1 & 39,9 & 42,0 & 36,3 \\
\% Material morto & 20,6 & 35,9 & 33,7 & 20,4 \\
Relação F:C & 1,03 & 0,61 & 0,58 & 1,19 \\
\hline
\end{tabular}

Disponibilidade de matéria seca total (DMST), matéria seca verde (DMSV), matéria seca potencialmente digestível (DMSpd), fibra em detergente neutro potencialmente digestível (DFDNpd), biomassa residual diária (BRD), taxa de lotação (TL), taxa de acúmulo diário (TAD), oferta de forragem (OF), altura da forragem (AF), percentual de folha, colmo e material morto, e relação folha:colmo $(\mathrm{F}: \mathrm{C})$.

Fonte: Elaboração dos autores. 
O acúmulo de MS, nos diferentes períodos experimentais, foi calculado multiplicando-se o valor da taxa de acúmulo diário (TAD) de MS pelo número de dias do período. As estimativas de biomassa residual diária (BRD) de matéria seca foram realizadas nos dois piquetes, conforme o método da dupla amostragem (WILM; COSTELLO; KLIPPLE, 1994). Utilizaram-se os valores das amostras cortadas e estimadas visualmente para cálculo da biomassa de forragem expressa em $\mathrm{kg} / \mathrm{ha}$ pela equação proposta por Gardner (1986).

A estimativa da TAD foi realizada pela equação proposta por Campbell (1966): TAD $_{J}=\left(G_{i}-F_{i}\right.$ $\left.{ }_{-1}\right) / \mathrm{n}$. Onde: $\mathrm{TADj}=$ taxa de acúmulo de matéria seca diária no período $\mathrm{j}$, em $\mathrm{kg} \mathrm{MS/ha} \mathrm{por} \mathrm{dia;} \mathrm{G}_{\mathrm{i}}=$ matéria seca final média dos dois piquetes vazios no instante $\mathrm{i}$, em $\mathrm{kg} \mathrm{MS} / \mathrm{ha} ; \mathrm{F}_{\mathrm{i}-1}=$ matéria seca inicial média presente nos piquetes vazios no instante $\mathrm{i}-1$, em $\mathrm{kg} \mathrm{MS} / \mathrm{ha}$; $\mathrm{n}=$ número de dias do período $\mathrm{j}$.

A taxa de lotação (TL) foi calculada considerando a unidade animal (UA) como sendo $450 \mathrm{~kg}$ de PV, utilizando-se a seguinte fórmula: $\mathrm{TL}=$ (UAt)/ área. Onde: TL = taxa de lotação, em UA/ha; UAt = unidade animal total; Área $=$ área experimental total, em ha.

A oferta de forragem (OF) foi calculada pela fórmula: $\mathrm{OF}=\{(\mathrm{BRD} *$ área $+\mathrm{TAD} *$ área $) /$ $\left.\mathrm{PC}_{\text {total }}\right\} * 100$. Onde: $\mathrm{OF}=$ oferta de forragem, em $\mathrm{kg}$ $\mathrm{MS} / 100 \mathrm{~kg}$ PV/dia; BRD = biomassa residual total, em $\mathrm{kg}$ de $\mathrm{MS} / \mathrm{ha} /$ dia; TAD = taxa de acúmulo diário, em $\mathrm{kg}$ MS/ha por dia; $\mathrm{PC}=$ peso corporal total dos animais, em $\mathrm{kg} / \mathrm{ha}$.

Foram calculadas a matéria seca e a fibra em detergente neutro potencialmente digestível (MSpd, FDNpd) do pasto, conforme descrito por (PAULINO; DETMANN; VALADARES, 2006), pelas seguintes equações: MSpd $=0,98(100-$ $\% \mathrm{FDN})+(\% \mathrm{FDN}-\% \mathrm{FDNi})$ e $\mathrm{FDNpd}=\% \mathrm{FDN}$ $-\% \mathrm{FDNi}$.

Para cálculo da disponibilidade de matéria seca e fibra em detergente neutro potencialmente digestível (DMSpd, DFDNpd) foi utilizado as equações:
DMSpd $=$ DMST $*$ MSpd, onde: DMSpd $=$ disponibilidade de matéria seca potencialmente digestível, em $\mathrm{kg} / \mathrm{ha}$; DMST = disponibilidade total de matéria seca, em $\mathrm{kg} / \mathrm{ha}$; MSpd = matéria seca potencialmente digestível, em percentual.

DFDNpd $=$ DMST $*$ FDNpd, onde: DFDNpd $=$ disponibilidade de fibra em detergente neutro potencialmente digestível, em $\mathrm{kg} / \mathrm{ha} ;$ DMST = disponibilidade total de matéria seca, em $\mathrm{kg} / \mathrm{ha}$; FDNpd = fibra em detergente neutro potencialmente digestível, em percentual.

Para estimar a produção fecal, utilizou-se o óxido de cromo como indicador externo, fornecido diariamente às 09:00 horas em dose única de 10 gramas acondicionada em papelote, durante 12 dias consecutivos, sendo sete dias para adaptação e regulação do fluxo de excreção do marcador e cinco dias (do oitavo ao décimo segundo) para coleta das fezes. Nos períodos de fornecimento do óxido de cromo, todos os animais foram conduzidos ao curral, todos os dias às 08:30 horas, colocados em compartimento coletivo e, em seguida, num tronco, o papelote era fornecido manualmente, sem contenção, por via oral.

As fezes foram coletadas uma vez ao dia, no próprio piquete, sempre no mesmo horário após o consumo de concentrado, imediatamente após a defecação, durante os últimos cinco dias, evitando contaminação por corpos estranhos. Posteriormente, foram armazenadas em câmara fria $\mathrm{a}-10^{\circ} \mathrm{C}$. As amostras de fezes foram analisadas por espectrofotometria de absorção atômica (EAA) para dosagem de cromo, conforme Williams (1962). A determinação da produção fecal foi realizada conforme a equação proposta por Smith e Reid (1955): $\mathrm{PF}=\mathrm{OF} / \mathrm{COF}$, onde: $\mathrm{PF}$ é a produção fecal diária ( $\mathrm{g} \mathrm{dia}^{-1}$ ); OF óxido de cromo fornecido ( $\mathrm{g}$ $\left.\operatorname{dia}^{-1}\right)$ e COF a concentração de óxido de cromo nas fezes $(\mathrm{g} / \mathrm{gMS})$.

Para análises do indicador interno, fibra em detergente ácido indigestível (FDAi) (CASALI et al., 2008), as amostras da forragem, das fezes e dos 
concentrados foram incubados no rúmen de quatro animais fistulados por $264 \mathrm{~h}$ (CASALI et al., 2008), tendo o resíduo sido assumido como indigestível.

Três dias antes de cada período de restrição ou realimentação, foram colhidas amostras de sangue de todos os animais, por venipunctura da veia jugular em tubos (Vacutainer ${ }^{T M}$ ) de $5 \mathrm{~mL}$, com EDTA. As amostras foram colhidas antes da alimentação matinal, sem jejum hídrico ou sólido, em seguida foram resfriadas a $10{ }^{\circ} \mathrm{C}$ e centrifugadas a 3.500 rpm por 10 minutos. O plasma foi acondicionado em Eppendorf e mantido congelado a $-20{ }^{\circ} \mathrm{C}$, para posteriores dosagens.

AsconcentraçõesdeIGF-I, insulina, progesterona, glicose, colesterol, proteína e uréia foram medidas para investigação das mudanças metabólicas e das concentrações hormonais associadas com a restrição alimentar e realimentação, no Laboratório de Fisiologia Animal do Departamento de Ciências Básicas - ZAB da Faculdade de Zootecnia e Engenharia de Alimentos - FZEA da Universidade de São Paulo - USP, Campus de Pirassununga, em leitora LabysystemsMultiskan MS, leitura $450 \mathrm{~nm}$.

As obtenções das concentrações de IGF-I no plasma foram realizadas por imunoensaio pós-extração utilizando o kit DSL-10-5600 ACTIVE ${ }^{\circledR}$ IGF-I ELISA (Diagnostic Systems Laboratories, Inc), segundo as indicações do fabricante.

Para as determinações de insulina e progesterona no plasma foram realizados procedimentos de enzima imunoensaio pelos kits INSULIN ACCUBIND Elisa Microwells, Code: 2425-300 e PROGESTERONE ACCU-BIND Elisa Microwells, Code: 4825-300 (Monobind Inc.) respectivamente, segundo as indicações do fabricante.

As concentrações de glicose, colesterol, proteína total e uréia no plasma foram determinadas por kits comerciais da empresa Laborlab ${ }^{\circledR}$, sendo a glicose e colesterol pelo método enzimático, proteína total pelo método colorimétrico e uréia pelo método enzimático, segundo as especificações do fabricante.

Utilizou-se o coeficiente de correlação linear de Pearson para avaliar as correlações entre as variáveis metabólicas. A significância dos coeficientes de correlação foi testada por meio do teste " $t$ " e processadas com auxilio do Sistema de Análises Estatísticas e Genéticas SAEG (RIBEIRO JUNIOR, 2001), sendo considerados significativos quando $\mathrm{P}<0,05$. A significância do coeficiente de correlação foi também interpretada de acordo com Shimakura (2006), onde " $r$ " assume valores entre -1 (associação linear negativa) e 1 (associação linear positiva), onde: 0,00 a 0,19 Correlações bem fracas; 0,20 a 0,39 Correlações fracas; 0,40 a 0,69 Correlações moderadas; 0,70 a 0,89 Correlações fortes e 0,90 a 1,00 Correlações muito fortes.

Os dados foram interpretados estatisticamente por meio de análise de variância e teste $\mathrm{F}$ considerando o efeito dos sistemas nutricionais (Controle e Nutrição Compensatória) e o efeito dos períodos (restrição e realimentação) em esquema fatorial 2 × 2 segundo o modelo estatístico:

$$
Y i j k=m+\alpha i+\beta j+(\alpha \beta) i j+\varepsilon i j k
$$

Sendo:

Yijk: o valor observado da variável em estudo

m: a média das unidades experimentais para a variável em estudo

ai: o efeito do sistema nutricional

$\beta \mathrm{j}$ : o efeito dos períodos

$(\alpha \beta) i j:$ o efeito da interação entre os sistemas nutricionais e os períodos

عijk: o erro associado a cada observação

\section{Resultados e Discussão}

As concentrações plasmáticas de metabólitos sanguíneos de novilhas mestiças suplementadas em pastagens e seus desdobramentos em função dos sistemas nutricionais e períodos são apresentadas nas tabelas 5,6 e 7 . 
As concentrações plasmáticas de insulina e proteína não sofreram $(\mathrm{P}>0,05)$ interferência dos sistemas nutricionais Controle e NC, nem dos períodos restrição e realimentação. As concentrações de colesterol e progesterona apresentaram diferenças $(P<0,05)$, entre os períodos, não sofrendo influência $(\mathrm{P}>0,05)$ dos sistemas nutricionais nem dos períodos. As concentrações plasmáticas de uréia variaram $(\mathrm{P}<0,05)$ tanto entre os sistemas nutricionais, como entre os períodos. O IGF-I e a glicose receberam influencia $(\mathrm{P}<0,05)$ dos sistemas nutricionais, e dos períodos (Tabela 5).

Tabela 5. Concentrações plasmáticas de metabólitos sanguíneos de novilhas mestiças suplementadas em pastagens.

\begin{tabular}{|c|c|c|c|c|c|c|c|c|}
\hline \multirow{2}{*}{ METABÓLITOS } & \multicolumn{2}{|c|}{ SISTEMA NUTRICIONAL } & \multicolumn{2}{|c|}{ PERÍODO } & \multirow{2}{*}{$\mathrm{CV}(\%)$} & \multicolumn{3}{|c|}{ Significância } \\
\hline & Controle & $\mathrm{NC}$ & Restrição & Realimentação & & $\mathrm{T}$ & $\mathrm{P}$ & TxP \\
\hline $\begin{array}{l}\text { IGF-I } \\
(\mathrm{ng} / \mathrm{mL})\end{array}$ & 368,62 & 495,15 & 324,57 & 539,20 & 20,79 & * & * & $*$ \\
\hline $\begin{array}{l}\text { INSULINA } \\
(\mu \mathrm{lU} / \mathrm{mL})\end{array}$ & 13,19 & 13,64 & 12,10 & 14,73 & 71,17 & ns & ns & ns \\
\hline $\begin{array}{l}\text { GLICOSE } \\
(\mathrm{mg} / \mathrm{dL})\end{array}$ & 96,95 & 110,39 & 99,44 & 107,90 & 11,62 & $*$ & $*$ & $*$ \\
\hline $\begin{array}{l}\text { COLESTEROL } \\
(\mathrm{mg} / \mathrm{dL})\end{array}$ & 133,15 & 130,68 & 122,52 & 141,31 & 14,75 & ns & $*$ & ns \\
\hline $\begin{array}{l}\text { PROGESTERONA } \\
(\mathrm{ng} / \mathrm{mL})\end{array}$ & 5,21 & 6,23 & 4,78 & 6,66 & 67,64 & ns & $*$ & ns \\
\hline $\begin{array}{l}\text { URÉIA } \\
\text { (mg/dL) }\end{array}$ & 93,68 & 80,11 & 95,80 & 77,99 & 31,10 & $*$ & $*$ & ns \\
\hline $\begin{array}{l}\text { PROTEÍNA } \\
(\mathrm{g} / \mathrm{dL})\end{array}$ & 5,06 & 5,03 & 4,99 & 5,11 & 18,51 & ns & ns & ns \\
\hline
\end{tabular}

(*) Significativo $(\mathrm{P}<0,05)$ e ns não significativo de acordo com o teste $\mathrm{F}$.

Fonte: Elaboração dos autores.

Cabe destacar que mesmo não existindo diferença estatística para as concentrações de insulina, verifica-se a tendência de elevação deste metabólito durante a realimentação, o que pode ser reflexo das diferenças $(\mathrm{P}<0,05)$ constatadas na concentração de glicose, que normalmente levam ao aumento na concentração de insulina. Esses resultados diferem dos estudos descritos por Choi et al. (1997) e Ford e Park (2001), que observaram que os níveis de insulina circulante diminuem durante períodos de restrição energética/proteica, mas aumentam durante a realimentação.

As concentrações de colesterol foram medidas devido à sua importância metabólica, pois, segundo Grummer e Carrol (1988), ele é o substrato utilizado pelas células luteínicas para a síntese de progesterona. Além disso, é o metabólito mais abundante no plasma e no fluido folicular (GRUMMER; CARROL, 1991). Portanto, os níveis de colesterol podem dar uma indicação indireta da atividade tireoidiana, sendo também indicadores adequados do total de lipídios do plasma (DIAZ GONZALEZ; SCHERER, 2002). O colesterol plasmático foi maior $(\mathrm{P}<0,05)$, nos períodos de realimentação, quando comparado com os períodos de restrição. Isso, entretanto, não foi suficiente para interferir $(\mathrm{P}>0,05)$ nas concentrações medidas entre os sistemas nutricionais Controle e NC.

Acompanhando os resultados das concentrações do colesterol, os níveis de progesterona plasmáticos foram maiores $(\mathrm{P}<0,05)$, nos períodos de realimentação, quando comparadas com os períodos de restrição. Também sem interferir $(\mathrm{P}>0,05)$ nas concentrações de progesterona medidas entre os 
sistemas nutricionais Controle e NC. A amplitude das concentrações de progesterona nos sistemas nutricionais Controle e $\mathrm{NC}$, encontrados no presente experimento $\left(5,21\right.$ a $6,23 \mathrm{ng} \mathrm{mL} \mathrm{m}^{-1}$, estão de acordo com experimentos realizados por Jiménez et al. (1988) e Badinga et al. (1994) que citam concentrações plasmáticas de progesterona em novilhas zebuínas e taurinas entre 1 e $16 \mathrm{ng} \mathrm{mL}^{-1}$.

No presente estudo, foi observado efeito negativo do regime de Nutrição Compensatória $(\mathrm{P}<0,05)$, sobre as concentrações plasmáticas de uréia com níveis superiores nos animais do Controle $\left(93,68 \mathrm{mg} \mathrm{dL}^{-1}\right)$ em relação aos animais do $\mathrm{NC}\left(80,11 \mathrm{mg} \mathrm{dL}^{-1}\right)$, este padrão também foi repetido nos resultados dos períodos que diferiram $(\mathrm{P}<0,05)$ entre os níveis plasmáticos da restrição $\left(95,80 \mathrm{mg} \mathrm{dL}^{-1}\right)$ e da realimentação $(77,99 \mathrm{mg} \mathrm{dL}-$ ${ }^{1}$ ), em discordância com o experimento de Hoch et al. (2003), que relataram diminuição da uréia com a aplicação de restrição alimentar em bovinos com recuperação dos valores séricos poucas horas após a realimentação.

Para avaliação do perfil proteico, via de regra recorre-se a determinação de uréia, albumina, globulina e proteína total séricas como indicadores, podendo a concentração plasmática de uréia servir para o monitoramento da ingestão de proteína bruta (PAYNE; PAYNE, 1987; DIRKSEN; GRUNDER; STOBER, 1993; LIMA et al., 2004). Discordando com esses resultados Oliveira Junior et al. (2004) concluíram que o nitrogênio ureico plasmático não é um bom indicador de consumo de proteína, mas pode ser utilizado para monitorar a proteína não utilizada.

Não foram observados efeitos significativos $(\mathrm{P}>0,05)$ entre os sistemas nutricionais, tampouco entre os períodos estudados sobre as concentrações de proteína. Isso pode ter decorrido da baixa severidade da restrição imposta aos animais. Apenas quando o animal é submetido à severa e gradual deficiência de energia, ocorre mobilização de proteína muscular para manutenção da homeostase energética, e em especial do teor de glicose sanguínea. Neste caso o animal deixa de depositar tecido muscular o que inibe o seu desenvolvimento. Para Luca e Reis (2001), níveis mais baixos de proteína plasmática são observados em casos de deficiência de proteína na dieta, insuficiência hepática, aproveitamento inadequado da proteína ingerida, hemorragias e perda de proteína intestinal ou renal.

Para Hoch et al. (2003), as adaptações do metabolismo energético e proteico permitem melhor aproveitamento dos alimentos por parte dos animais. Esses processos adaptativos normalmente dependem da ingestão de alimentos e são regulados pelos hormônios insulina, imunoglobulinas e hormônio do crescimento, resultando em menor requerimento energético e síntese de proteína muscular, podendo haver diminuição do crescimento e do ganho de peso e até comprometimento do inicio da vida reprodutiva.

Houve interação $(\mathrm{P}<0,05)$ entre os níveis plasmáticos de IGF-I testados para os sistemas nutricionais e períodos. No período de restrição não ocorreu diferença $(\mathrm{P}>0,05)$ entre os sistemas Controle e NC. Já no período de realimentação o Controle foi inferior $(\mathrm{P}<0,05), 20,70 \%$ em relação ao NC. Os valores plasmáticos de IGF-I constatados no período de restrição foram menores $(\mathrm{P}<0,05)$ para os Sistemas Controle e NC em relação ao período de realimentação (Tabela 6). O IGF-I é citado por Hogg (1991), como sendo um hormônio relacionado com o desenvolvimento compensatório, apresentando grande correlação entre os níveis de GH e IGF-I. O teor de GH no sangue aumenta a produção de IGF-I e esse, por sua vez, diminui a produção de GH. As maiores concentrações plasmáticas de IGF-I verificadas durante a realimentação, e, por analogia menores concentrações de GH, estão em consonância com a literatura (HOUSEKNECHT et al., 1988; THOMAS et al., 1991; CHOI et al., 1997). 
Tabela 6. Desdobramento dos valores de IGF-I em função dos sistemas nutricionais e períodos.

\begin{tabular}{lcc}
\hline Sistema Nutricional & Pestrição & Períos \\
\hline Controle $(\mathrm{ng} / \mathrm{mL})$ & $316,06 \mathrm{Ab}$ & Realimentação \\
$\mathrm{NC}(\mathrm{ng} / \mathrm{mL})$ & $333,09 \mathrm{Ab}$ & $421,18 \mathrm{Ba}$ \\
\hline
\end{tabular}

Letras maiúsculas comparam as médias nas colunas e minúsculas nas linhas pelo teste $\mathrm{F}(\mathrm{P}<0,05)$.

Fonte: Elaboração dos autores.

Cabaraux et al. (2005) encontraram valor divergente de IGF-I circulante, em vacas Belgian Blue em engorda, que foi de 104,6 $\mathrm{ng} \mathrm{mL}^{-1}$. Os autores acreditam que as diferenças para os valores mais altos normalmente encontrados em novilhas, como no presente experimento, podem ocorrer pela migração do hormônio para os tecidos periféricos, em decorrência do maior desenvolvimento muscular.

Houve interação $(\mathrm{P}<0,05)$ entre os níveis plasmáticos de glicose testados para os sistemas nutricionais e períodos. No período de restrição não ocorreu diferença $(\mathrm{P}>0,05)$ entre os sistemas Controle e NC. Já no período de realimentação o sistema Controle foi inferior $(\mathrm{P}<0,05), 24,77 \%$ em relação ao NC. Os valores plasmáticos de glicose constatados no Controle foram superiores $(\mathrm{P}<0,05)$ no período de restrição $\left(101,25 \mathrm{mg} \mathrm{dL}^{-1}\right)$ em relação ao período de realimentação $\left(92,65 \mathrm{mg} \mathrm{dL}^{-1}\right)$. Já no sistema NC o período de realimentação $(123,15 \mathrm{mg}$ $\left.\mathrm{dL}^{-1}\right)$ foi superior $(\mathrm{P}<0,05)$ em relação ao período de restrição $\left(97,64 \mathrm{mg} \mathrm{dL}^{-1}\right)$, (Tabela 7$)$.

Tabela 7. Desdobramento dos valores de Glicose em função dos sistemas nutricionais e períodos.

\begin{tabular}{lcc}
\hline \multirow{2}{*}{ Sistemas Nutricionais } & \multicolumn{2}{c}{ Períodos } \\
& Restrição & Realimentação \\
\hline Controle $(\mathrm{mg} / \mathrm{dL})$ & $101,25 \mathrm{Aa}$ & $92,65 \mathrm{Bb}$ \\
$\mathrm{NC}(\mathrm{mg} / \mathrm{dL})$ & $97,64 \mathrm{Ab}$ & $123,15 \mathrm{Aa}$ \\
\hline
\end{tabular}

Letras maiúsculas comparam as médias nas colunas e minúsculas nas linhas pelo teste $\mathrm{F}(\mathrm{P}<0,05)$.

Fonte: Elaboração dos autores.

Resultados semelhantes foram obtidos por Maruta (2005) e Sucupira (2003) que observaram diminuição da glicemia durante a restrição. (YAMBAYAMBA; PRICE; FOXCROFT, 1996) verificaram nos primeiros 20 dias uma queda significativa de $14 \%$ para a glicose e no dia 48 , uma queda significativa de $16 \%$ em relação ao lote Controle. Hornick et al. (1998) Lima (2005), obtiveram uma queda de $15 \%$ na concentração de glicose quando comparado com o grupo Controle. No presente experimento, houve queda $(\mathrm{P}<0,05)$ de $20,71 \%$ no período de restrição.
Na Tabela 8 são demonstradas as correlações entre as variáveis metabólicas ao final do experimento. Verifica-se que o IGF-I apresenta $(\mathrm{P}<0,05)$, correlação positiva bem fraca com a insulina, positiva moderada com a glicose, positiva fraca com o colesterol e negativa fraca com a uréia. Não apresenta correlação com os demais metabólitos. Dentre os metabólitos o IGF-I é aquele de maior número de correlações, confirmando vários estudos que o apontam como sendo um dos hormônios mais relacionados com o desenvolvimento compensatório (HOUSEKNECHT et al., 1988; DAUGHADAY; ROTWEIN, 1989; THOMAS et al., 1991; HOGG, 1991; CHOI et al., 1997; YAKAR et al., 2002). 
Tabela 8. Correlações entre as variáveis metabólicas ao final do experimento.

\begin{tabular}{|c|c|c|c|c|c|c|c|}
\hline VARIÁVEL & 壳 & $\begin{array}{l}\overleftrightarrow{Z} \\
Z \\
\text { 号 } \\
\text { Z }\end{array}$ & $\begin{array}{l}\text { yn } \\
0 \\
0 \\
0 \\
0\end{array}$ & 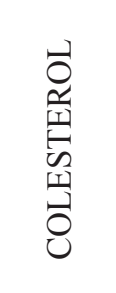 & 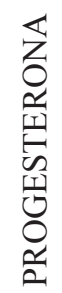 & 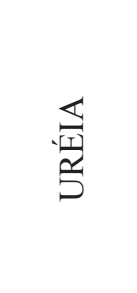 & 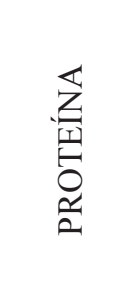 \\
\hline IGF-I & -- & 0,1923 & 0,5317 & 0,3753 & -- & $-0,3609$ & -- \\
\hline INSULINA & & -- & 0,2032 & -- & -- & -- & -- \\
\hline GLICOSE & & & -- & 0,2638 & -- & -- & -- \\
\hline COLESTEROL & & & & -- & -- & $-0,2649$ & -- \\
\hline PROGESTERONA & & & & & -- & $-0,3883$ & 0,3359 \\
\hline URÉIA & & & & & & -- & $-0,4039$ \\
\hline PROTEÍNA & & & & & & & -- \\
\hline
\end{tabular}

Coeficiente de correlação linear de Pearson - As correlações apresentadas são significantes pelo Teste "T" $(\alpha=5 \%)$

Fonte: Elaboração dos autores.

A insulina, além da correlação com o IGF-I também apresenta correlação positiva fraca com a glicose $(\mathrm{P}<0,05)$. A insulina é um dos principais hormônios metabólicos, com efeitos diretos na divisão celular e produção da progesterona, tendo papel fundamental na reprodução, manutenção da glicemia e secreção de IGF-I.

A glicose, como já demonstrado, apresenta correlações positivas com o IGF-I e com a insulina. Trabalho de (MAGGIONI; ROTTA; ITO, 2008), também demonstrou correlação positiva fraca da glicose com o colesterol.

O colesterol, além das correlações positivas com o IGF-I e com a glicose, demonstrou correlação negativa fraca $(\mathrm{P}<0,05)$ com a uréia, sem interferir nem sofrer interferência dos demais metabólitos.

A progesterona demonstrou correlação positiva fraca $(\mathrm{P}<0,05)$ com a proteína e negativa fraca com a uréia, corroborando com vários estudos que apontam a elevação da progesterona plasmática paralela ao crescimento dos níveis proteicos. A correlação negativa com a uréia é decorrente do grande aporte desse metabólito para formação dos aminoácidos que compõem as estruturas proteicas.
A uréia, além das correlações negativas com IGF-I, colesterol e progesterona, também apresentou correlação negativa moderada $(\mathrm{P}<0,05)$ com a proteína por ser amplamente utilizada na síntese dessa molécula.

\section{Conclusões}

O manejo nutricional que alterna períodos de restrição energética/proteica e realimentação de novilhas mestiças em pastejo, durante a prépuberdade interfere nas interações e sínteses de metabólitos e hormônios importantes para o crescimento e reprodução, elevando os níveis plasmáticos de IGF-I, glicose e uréia e não influencia nas concentrações plasmáticas de insulina, colesterol, progesterona e proteína.

O trabalho foi aprovado pelo Comitê de Ética no Uso de Animais - CEUA/UESB, sob o Protocolo $n^{\circ}$ $16 / 2012$. 


\section{Referências}

ASSOCIATION OF OFFICIAL ANALYTICAL CHEMISTS - AOAC. Official methods of analysis. 16. ed. Washington, 1995. $1094 \mathrm{p}$.

BADINGA, L.; THATCHER, W. W.; WILCOX, C. J.; MORRIS, G.; ENTWISTLE, E.; WOLFENSON, D. Effect of season on follicular dynamics and plasma concentrations of estradiol-17 $\beta$, progesterone and luteinizing hormone in lactating Holstein cows. Theriogenology, Philadelphia, v. 42, n. 1, p. 1263-1274, 1994.

CABARAUX, J. F.; DUFRASNE, I.; ISTASSE, L.; HORNICK, J. L. Variation of plasma parameters and nitrogen metabolism in finishing Belgian Blue doublemuscled cull females. Journal of Animal Physiology and Animal Nutrition, München, v. 89, n. 1, p. 55-62, 2005.

CAMPBELL, A. G. Grazed pastures parameters; I. Pasture dry-matter production and availability in a stocking rate and grazing management experiment with dairy cows. Journal Agricultural Science, Cambridge, v. 67, n. 1, p. 211-216, 1966.

CASALI, A. O.; DETMANN, E.; VALADARES FILHO, S. C.; PEREIRA, J. C.; HENRIQUES, L. T.; FREITAS, S. G. de; PAULINO, M. F. Influência do tempo de incubação e do tamanho de partículas sobre os teores de compostos indigestíveis em alimentos e fezes bovinas obtidos por procedimentos in situ. Revista Brasileira de Zootecnia, Viçosa, MG, v. 37, n. 2, p. 335-342, 2008.

CHOI, Y. J.; HAN, I. K.; WOO, J. H.; LEE, H. J.; JANG, K.; MYUNG, K. H,; KIM, Y. S. Compensatory growth in dairy heifers: the effect of a compensatory growth pattern on growth rate and lactation performance. Journal of Dairy Science, Champaign, v. 80, n. 1, p. 519-524, 1997.

DAUGHADAY, W. H.; ROTWEIN, P. Insulin-like growth factors I and II. Peptide, messenger ribonucleic acid and gene structures, serum and tissue concentration. Endocrine Reviews, Chicago, v. 10, n. 1, p. 68-92, 1989.

DIAZ GONZALEZ, F. H.; SCHERER, J. F. S. Perfil sanguíneo: ferramenta de análise clinica, metabólica e nutricional. In: CONGRESSO BRASILEIRO DE MEDICINA VETERINARIA, 29., 2002, Gramado. Anais... Gramado: SOVERGS, 2002. p. 150-157.

DIRKSEN, G.; GRUNDER, H.; STOBER, M. R. Exame clínico dos bovinos. 3. ed. Rio de Janeiro: Koogan, 1993. $429 \mathrm{p}$.

FORD, F. A.; PARK, C. S. Nutritionally directed compensatory growth enhances heifer development and lactation potential. Journal of Dairy Science, Champaign, v. 84, n. 1, p.1669-1678, 2001.
GARDNER, A. L. Técnicas de pesquisa em pastagem e aplicabilidade de resultados em sistema de produção. Brasília: IICA/EMBRAPA CNPGL, 1986. 197 p.

GRUMMER, R. R.; CARROL, D. J. A review of lipoprotein cholesterol metabolism: importance to ovarian function. Journal of Animal Science, Champaign, v. 66, n. 3, p. 3160-3173, 1988.

Effects of dietary fat on metabolic disorders and reproductive performance of dairy cattle. Journal of Animal Science, Champaign, v. 69, n. 3, p. 3838-3852, 1991.

HOCH, T.; BEGON, C.; CASSAR, M. I.; PICARD, B.; SAVARY, A. I. Mecanismes et consequences de la croissance compensatrice chez les ruminants. INRA Productions Animales, Saint-Genès, v. 16, n. 1, p. 49-59, 2003.

HOGG, B. W. Compensatory growth in ruminants. Elsevier Science, London, v. 7, n. 5, p. 103-114, 1991.

HORNICK, J. L.; EENAEME, V. C.; DIEZ, M.; MINET, V.; ISTASSE, L. Different periods of feed restriction before compensatory growth in Belgian Blue. Journal of Animal Science, Champaign, v. 76, n. 2, p. 260-271, 1998.

HOUSEKNECHT, K. L.; BOGGS, D. L.; CAMPION, D. R.; SARTIN, J. L.; KISER, T. E.; RAMPACEK, G. B.; AMOS, H. E. Effect of dietary energy source and level on serum growth hormone, insulin-like growth factor 1, growth and body composition in beef heifers. Journal of Animal Science, Champaign, v. 66, n. 11, p. 2918-2922, 1988.

JIMÉNEZ, F.; GALINA, C. S.; DUCHATEAU, A.; NAVARRO FIERO, R. Levels of LH, progesterone and estradiol 17beta during natural and PGF2 alfa induced estrus in Indubrazil and Brown Swiss cows in the tropics. Animal Reproductions Science, Cambridge, v. 16, n. 2, p. 199-203, 1988.

JOHNSON, A. D. Sample preparation and chemical analysis of vegetation. In: MANETJE, L. T. (Ed.). Measurement of grassland vegetation and animal production. Aberustwyth: Commonwealth Agricultural Bureaux, 1978. p. 96-102.

LIMA, A. S. Avaliação do perfil hormonal de garrotes submetidos à carência energética prolongada. 2005. Dissertação (Mestrado em Medicina Veterinária) - Faculdade de Medicina Veterinária e Zootecnia, Universidade de São Paulo, São Paulo. Disponível em: $<$ http://www.teses.usp.br/teses/disponiveis/10/10136/ tde-09022007-153232/pt-br.php>. Acesso em: 21 jun. 2012. 
LIMA, M. L. P.; BERCHIELLI, T. T.; LEME, P. R.; NOGUEIRA, J. R.; PINHEIRO, M. da G. Concentração de nitrogênio ureico plasmático (NUP) e produção de leite de vacas mestiças em gramíneas tropicais sob pastejo rotacionado. Revista Brasileira de Zootecnia, Viçosa, MG, v. 33, n. 6, p. 1616-1626, 2004.

LUCA, G. C.; REIS, B. F. Espectrofotometria de proteínas totais em plasma de sangue bovino por análise em fluxo. Scientia Agricola, Piracicaba, v. 59, n. 2, p. 251-256, abr./jun. 2001.

MAGGIONI, D.; ROTTA, P. P.; ITO, R. H. Efeito da nutrição sobre a reprodução de ruminantes: uma revisão. PUBVET, Londrina, v. 2, n. 11, p. 33-36, 2008.

MARUTA, C. A. Perfil metabólico e ruminal de garrotes submetidos às condições de alimentação normal, jejum e realimentação. 2005. Tese (Doutorado em Medicina Veterinária) - Faculdade de Medicina Veterinária e Zootecnia, Universidade de São Paulo, São Paulo, 2005. Disponível em: <http://www.teses.usp.br/teses/ disponiveis/10/10136/tde-15042008-140504/pt-br.php>. Acesso em: 04 set. 2012.

MCMENIMAN, N. P. Methods of estimating intake of grazing animals. In: REUNIÃO ANUAL DA SOCIEDADE BRASILEIRA DE ZOOTECNIA, SIMPÓSIO SOBRE TÓPICOS ESPECIAIS EM ZOOTECNIA, 34., 1997, Juiz de Fora. Anais... Juiz de Fora: Sociedade Brasileira de Zootecnia, 1997. p. 131168.

MERTENS, D. R. Gravimetric determination of amylasetreated neutral detergent fiber in feeds with refluxing in beakers or crucibles: collaborative study. Journal of AOAC International, Washington, v. 85, n. 1, p. $1217-$ 1240, 2002.

NATIONAL RESEARCH COUNCIL - NRC. Nutrient requeriments of dairy cattle. 7. ed. Washington: National Academy Press, 2001.

OLIVEIRA FILHO, B. D.; GAMBARINI, M. L.; TONIOLLO, G. H. Efeitos da suplementação nutricional pré e pós parto e da condição corporal ao parto sobre a reprodução, em vacas de corte. Revista Brasileira de Reprodução Animal, Belo Horizonte, v. 21, n. 2, p. 112$113,1997$.

OLIVEIRAJUNIOR, R. C.; PIRES, A. V.; FERNANDES, J. J. R.; SUSIN, I.; SANTOS, F. A. P.; ARAÚJO, R. C. Substituição total do farelo de soja por uréia ou amiréia, em dietas com alto teor de concentrado, sobre a amônia ruminal, os parâmetros sanguíneos e o metabolismo de nitrogênio em bovinos de corte. Revista Brasileira de Zootecnia, Viçosa, MG, v. 33, n. 3, p. 727-748, 2004.
PARK, S. C.; ERICKSON, G. M.; CHOI, Y. J.; MAX, G. D. Effects of compensatory growth on regulation of growth and lactation: response of dairy heifers to a stair-step growth pattern. Journal of Animal Science, Champaign, v. 64, n. 6, p. 1751-1758, 1987.

PAULINO, M. F.; DETMANN, E.; VALADARES FILHO, S. C. Suplementação animal em pasto: energética ou protéica? In: SIMPÓSIO SOBRE MANEJO ESTRATÉGICO DA PASTAGEM, 3., 2006, Viçosa, MG. Anais... Viçosa, MG: SIMFOR, 2006. p. 359-392.

PAYNE, J. M.; PAYNE, S. The metabolic profile test. Oxford: Oxford University Press, 1987. 179 p.

RIBEIRO JUNIOR, J. I. Análises estatísticas no SAEG: sistema de análises estatísticas. UFV. Viçosa, MG. 2001. $301 \mathrm{p}$.

SHIMAKURA, S. E. Interpretação do coeficiente de correlação. [S.1.: s.n], 2006. 193 p. Disponível em: $<$ http://leg.ufpr.br/ silvia/CE003/node74.html>. Acesso em: 04 set. 2012.

SMITH, A. M.; REID, J. T. Use of chromic oxide as an indicator of fecal output for the purpose of determining the intake of a pasture herbage by grazing cows. Journal of Dairy Science, Champaign, v. 38, n. 5, p. 515-524, 1955.

SNIFFEN, C. J.; O’CONNOR, J. D.; VAN SOEST, P. J.; FOX, D. G.; RUSSEL, J. B. A net carbohydrate and protein system for evaluating cattle diets: IICarbohydrate and protein availability. Journal of Animal Science, Champaign, v. 70, n. 1, p. 3562-3577, 1992.

SUCUPIRA, M. C. A. Estudo comparativo de exames clínico-laboratoriais no diagnóstico de carência energética prolongada em garrotes. 2003. Tese (Doutorado em Clinica Veterinária) - Faculdade de Medicina Veterinária e Zootecnia, Universidade de São Paulo, São Paulo. Disponível em: <http:// www3.fmvz.usp.br:8080/index.php/site/content/ versionview/5255/1>. Acesso em: 04 set. 2012.

THOMAS, G. B.; CUMMINGS, J. T.; FRANCIS, H.; SUDBURY, A. W.; McClOUD, P. I.; CLARKE, I. J. Effect of restricted feeding on the relationship between hypophysial portal concentration of growth hormone realeasing factor and somatostatin, and jugular concentrations of $\mathrm{GH}$ in ovariectomized ewes. Endocrinology, Washington, v. 128, n. 2, p. 1151-1158, 1991.

VAN SOEST, P. J.; ROBERTSON, J. B.; LEWIS, B. A. Methods for dietary fiber, neutral detergent fiber, and nonstarch polysaccharides in relation to animal nutrition. Journal of Dairy Science, Champaign, v. 74, n. 10, p. 3583-3597, 1991. 
WEISS, W. P. Energy prediction equations for ruminant feeds. In: CORNELL NUTRITION CONFERENCE FOR FEED MANUFACTURERS, 61., 1999, Ithaca. Proceedings... Ithaca: Cornell University, 1999. p. 176181.

WHITLOCK, B. K.; VANDEHAAR, M. J.; SILVA, L. F. P.; TUCKER, H. A. Effect of dietary protein on prepubertal mammary development in rapidly growing dairy heifers. Journal of Dairy Science, Champaign, v. 85, n. 10, p. 1516-1525, 2002.

WILLIAMS, C. H. Determination of chromic oxide in faeces samples by atomic absorption sectrophotometry. Journal of Agricultural Science, Cambridge, v. 59, n. 3, p. 381-385, 1962.
WILM, H. G.; COSTELLO, D. F.; KLIPPLE, G. E. Estimating forage yield by the double sampling method. Journal of American Society of Agronomy, Madison, v. 36, n. 3, p. 194-203, 1994.

YAKAR, S.; WU, Y.; SETSER, J.; ROSEN, C. J. The role of circulating IGF-I: lessons from human and animal models. Endocrine, Washington, v. 3, n. 19, p. 239-248, 2002.

YAMBAYAMBA, E. S.; PRICE, M. A.; FOXCROFT, G. R. Hormonal status, metabolic changes, and resting metabolic rate in beef heifers undergoing compensatory growth. Journal of Animal Science, Champaign, v. 74, n. 2, p. 57-69, 1996. 